\title{
Iodine Deficiency and Mortality in Spanish Adults: Di@bet.es Study
}

\author{
Cristina Maldonado-Araque,,2 Sergio Valdés,, ${ }^{1,2}$ Rocío Badía-Guillén,1 Ana Lago-Sampedro,,2 \\ Natalia Colomo, ${ }^{1,2}$ Eduardo Garcia-Fuentes, ${ }^{3}$ Carolina Gutierrez-Repiso, ${ }^{4,5}$ Albert Goday, ${ }^{6}$ \\ Alfonso Calle-Pascual, ${ }^{2,7}$ Luis Castaño, ${ }^{2,8,9}$ Conxa Castell, ${ }^{10}$ Elías Delgado, ${ }^{9,11}$ Edelmiro Menendez, ${ }^{9,11}$ \\ Josep Franch-Nadal, ${ }^{2,12}$ Sonia Gaztambide, ${ }^{2,9,13}$ Joan Girbés, ${ }^{14}$ Francisco Javier Chaves, ${ }^{2,15}$ \\ Federico Soriguer, ${ }^{1,2}$ and Gemma Rojo-Martínez ${ }^{1,2}$
}

Background: Longitudinal data assessing the impact of iodine deficiency (ID) on mortality are scarce. We aimed to study the association between the state of iodine nutrition and the risk of total and cause-specific mortality in a representative sample of the Spanish adult population.

Methods: We performed a longitudinal observational study to estimate mortality risk according to urinary iodine (UI) concentrations using a sample of 4370 subjects $>18$ years representative of the Spanish adult population participating in the nationwide study Di@bet.es (2008-2010). We used Cox regression to assess the association between UI at the start of the study $(<50,50-99,100-199,200-299$, and $\geq 300 \mu \mathrm{g} / \mathrm{L})$ and mortality during followup (National death registry - end of follow-up December 2016) in raw models, and adjusted for possible confounding variables: age, sex, educational level, hypertension, diabetes, obesity, chronic kidney disease, smoking, hypercholesterolemia, thyroid dysfunction, diagnosis of cardiovascular disease or cancer, area of residence, physical activity, adherence to Mediterranean diet, dairy and iodinated salt intake.

Results: A total of 254 deaths were recorded during an average follow-up period of 7.3 years. The causes of death were cardiovascular 71 (28\%); cancer 85 (33.5\%); and other causes 98 (38.5\%). Compared with the reference category with adequate iodine nutrition (UI 100-300 $\mu \mathrm{g} / \mathrm{L}$ ), the hazard ratios (HRs) of all-cause mortality in the category with UI $\geq 300 \mu \mathrm{g} / \mathrm{L}$ were 1.04 (95\% confidence interval [CI 0.54-1.98]); however, in the categories with 50-99 UI and $<50 \mu \mathrm{g} / \mathrm{L}$, the HRs were 1.29 [CI 0.97-1.70] and 1.71 [1.18-2.48], respectively ( $p$ for trend 0.004). Multivariate adjustment did not significantly modify the results.

Conclusions: Our data indicate an excess mortality in individuals with moderate-severe ID adjusted for other possible confounding factors.

Keywords: iodine, mortality, epidemiology, Spain

\footnotetext{
${ }^{1}$ Department of Endocrinology and Nutrition, Hospital Regional Universitario de Málaga, Instituto de Investigación Biomedica de Málaga-IBIMA, Málaga, Spain.

${ }^{2}$ Centro de Investigación Biomédica en Red de Diabetes y Enfermedades Metabólicas Asociadas (CIBERDEM), Instituto de Salud Carlos III, Madrid, Spain.

${ }^{3}$ UGC de Aparato Digestivo, Hospital Universitario Virgen de la Victoria, Instituto de Investigación Biomedica de Málaga-IBIMA, Málaga, Spain. ${ }^{4}$ CIBER de Fisiopatología de la Obesidad y Nutrición (CIBEROBN), Instituto de Salud Carlos III, Madrid, Spain.

${ }^{5}$ Department of Endocrinology and Nutrition, Hospital Universitario Virgen de la Victoria, Instituto de Investigagión Biomedica de Málaga-IBIMA, Málaga, Spain.

${ }^{6}$ Department of Endocrinology and Nutrition, Hospital del Mar, Barcelona, Spain.

${ }_{8}^{7}$ Department of Endocrinology and Nutrition, Hospital Universitario S. Carlos de Madrid, Madrid, Spain.

${ }^{8}$ Hospital Universitario Cruces, BioCruces Bizkaia, UPV/EHU, Barakaldo, Spain.

${ }^{9}$ Centro de Investigación Biomédica en Red de Enfermedades Raras (CIBERER), Instituto de Salud Carlos III, Madrid, Spain.

${ }^{10}$ Department of Health, Public Health Agency of Catalonia, Barcelona, Spain.

${ }^{11}$ Department of Endocrinology and Nutrition, Hospital Universitario Central de Asturias/University of Oviedo, Instituto de Investigación Sanitaria del Principado de Asturias (ISPA), Oviedo, Spain.

${ }^{12}$ EAP Raval Sud, Institut Català de la Salut, Red GEDAPS, Primary Care, Unitat de Suport a la Recerca (IDIAP_Fundació Jordi Gol), Barcelona, Spain.

${ }_{13}^{13}$ Department of Endocrinology and Nutrition, Hospital Universitario Cruces, BioCruces Bizkaia, UPV/EHU, Barakaldo, Spain.

${ }^{14}$ Diabetes Unit, Hospital Arnau de Vilanova, Valencia, Spain.

${ }^{15}$ Genomic Studies and Genetic Diagnosis Unit, Fundación de Investigación del Hospital Clínico de Valencia-INCLIVA, Valencia, Spain.

(C) Cristina Maldonado-Araque et al., 2020; Published by Mary Ann Liebert, Inc. This Open Access article is distributed under the terms of the Creative Commons Attribution Noncommercial License (http://creativecommons.org/licenses/by-nc/4.0/) which permits any noncommercial use, distribution, and reproduction in any medium, provided the original author(s) and the source are cited.
} 


\section{Introduction}

ODINE IS A trace element that is essential for the synthesis of thyroid hormones. Iodine deficiency (ID) can lead to goiter, thyroid dysfunction, cognitive impairment, and delayed physical development (1).

Despite progress in strategies for preventing and controlling ID, ID disorders continue to be a major public health problem throughout the world. It is estimated that $>2000$ million people worldwide are still at risk of insufficient iodine intake, 459.7 million in Europe (2). In Spain, although the evolution of iodine nutrition in recent years has been favorable placing our country globally as with "adequate iodine nutrition," there is still evidence that a large proportion of the population remains iodine deficient (3). Moreover, there is a lack of policies concerning monitoring systems on the population iodine status, or in the prevention of ID, such as universal salt iodization, as recommended by the World Health Organization (WHO) and United Nations International Children's Emergency Fund (UNICEF) (4).

As most iodine ingested by the body is excreted in urine (90\%), urinary iodine (UI) reflects recent dietary iodine intake, therefore the assessment of iodine intake is mostly based on urinary excretion. Studies have convincingly demonstrated that a profile of iodine concentrations in morning or other random urine specimens provides an adequate assessment of a population's iodine nutrition, when provided by a sufficient number of individuals (1).

Assessing an association between ID and mortality beyond its effects on thyroid function would stress the need to implement preventive strategies focused on its eradication. However, longitudinal data studying the impact of iodine nutrition on mortality are scarce.

The aim of this study was to investigate if there is an association between the state of iodine nutrition, measured as $\mathrm{UI}$ in a random urine sample, and the risk of total and causespecific mortality in a representative sample of the Spanish adult population.

\section{Materials and Methods}

\section{Population}

The Di@bet.es Study is a national, cross-sectional, population-based survey conducted in 2009-2010 (5-7). A cluster sampling design was used to select participants to form a representative random sample of the Spanish population. One hundred health centers or their equivalent from all around the country were selected randomly, with a probability for selection proportional to their target population size (Fig. 1), after which 100 individuals aged $\geq 18$ years were randomly selected from each health center. Of the eligible adults, $55.8 \%$ were evaluated, and $9.9 \%$ were excluded (because they were institutionalized, had severe disease, were pregnant, or recently delivered), resulting in a final sample of 5072 individuals.

We selected 4383 subjects for this study for whom UI measurements were available. In addition, we excluded 13 subjects on treatment with amiodarone, usually prescribed for cardiac arrhythmia, which contents a high amount of iodine in its composition. All these 13 subjects had UI concentrations $>400 \mu \mathrm{g} / \mathrm{L}$.

The research was carried out in accordance with the Declaration of Helsinki (8) of the World Medical Association. Written informed consent was obtained from all the participants. The study was approved by the Ethics and Clinical Investigation Committee of the Hospital Regional Universitario de Málaga (Malaga, Spain) in addition to other regional ethics and clinical investigation committees all over Spain.

\section{Variables and procedures}

The participants were invited to attend a single examination visit at their health center. Information was collected using an interviewer administered structured questionnaire, followed by a physical examination and blood and urine sampling.

Information on age, sex, educational level, smoking status, and other sociodemographic variables was obtained using

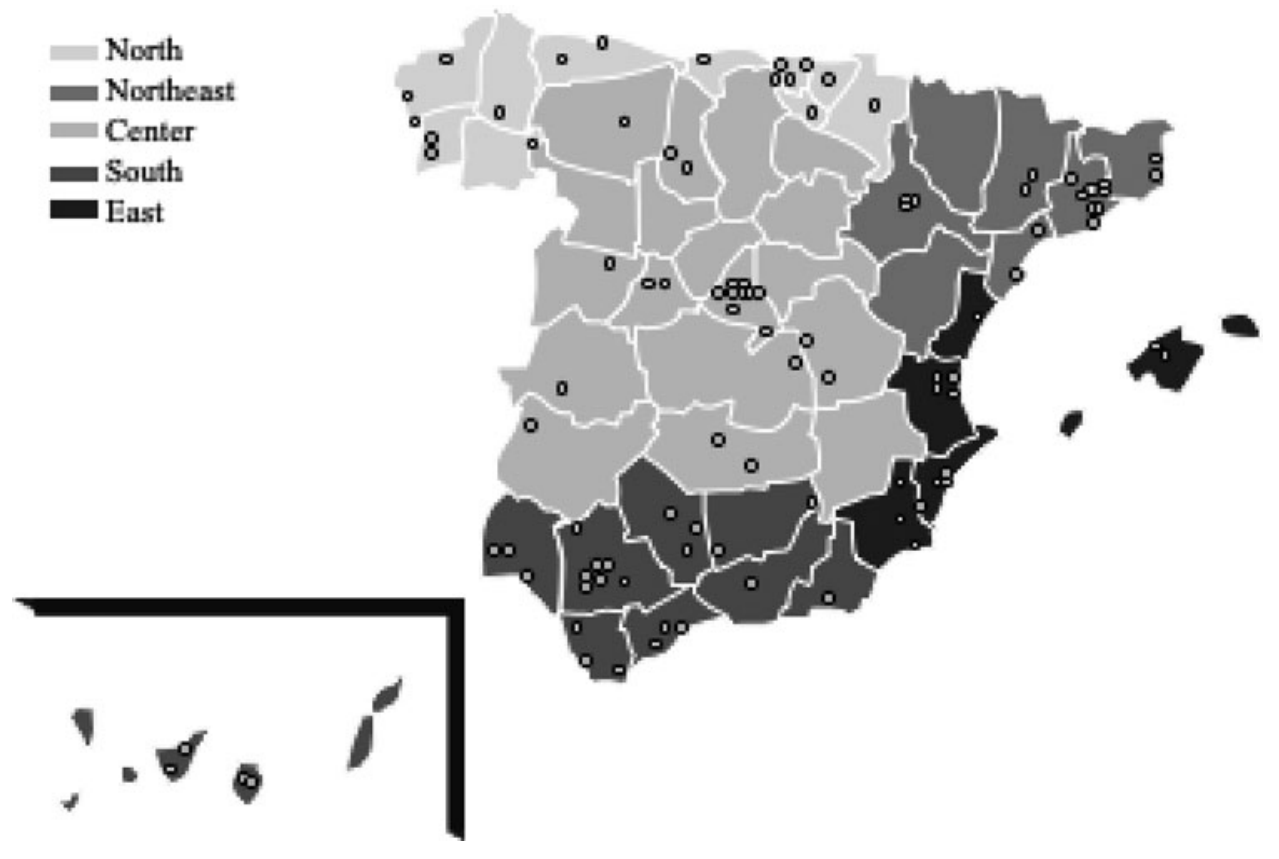

FIG. 1. Map showing the 100 clusters included in the Di@bet.es study. Geographical zones are indicated. 
a questionnaire. Food consumption was determined by a 40-item food frequency questionnaire. The questionnaire included the assessment of dairy and iodinated salt consumption. Adherence to a Mediterranean diet was estimated by a modified version of a validated 14-item Mediterranean diet score (MedScore) (9). The level of daily physical activity was estimated by the short form of the International Physical Activity Questionnaire (10). Self-reported previous diagnoses of cardiovascular disease and cancer were also recorded.

Weight and height were measured by standardized methods. The body mass index (BMI) was calculated. A BMI $\geq 30 \mathrm{~kg} / \mathrm{m}^{2}$ was considered as representing obesity (11). Blood pressure was measured using a blood pressure monitor (Hem-703C; Omron, Barcelona, Spain) after several minutes in a seated position; the mean of two measurements taken after at least two minutes apart was used for analysis. Hypertension was considered if there was a previous clinical diagnosis of hypertension, and/or systolic blood pressure was $\geq 140 \mathrm{mmHg}$ and/or diastolic blood pressure was $\geq 90 \mathrm{mmHg}$ (12).

Participants with baseline capillary blood glucose levels $<7.8 \mathrm{mmol} / \mathrm{L}$ (measured by OneTouch ${ }^{\circledR}$ system; Lifescan, Johnson \& Johnson, S.A.) and not receiving treatment for diabetes mellitus (DM) underwent a standard oral glucose tolerance test, obtaining fasting and two hours venous samples (8-10 hours fasting samples were obtained between 8:30 a.m. and 10:00 a.m.). Samples were immediately centrifuged, and the serum was frozen until analysis.

Serum glucose, triglycerides, and cholesterol were measured enzymatically and high-density lipoprotein cholesterol by a direct method. The diagnosis of DM was based on the 1999 WHO criteria (13). Hypercholesterolemia was defined as total cholesterol concentration $\geq 240 \mathrm{mg} / \mathrm{dL}$ or treatment with lipid lowering drugs (14).

Creatinine was analyzed with the modified Jaffe method (Randox Laboratories Ltd., Antrim, United Kingdom), using an A15 autoanalyzer (BioSystems, Barcelona, Spain) (15). Estimated glomerular filtration rate (eGFR) was calculated according to the Chronic Kidney Disease Epidemiology Collaboration (CKD-EPI) equation (16). CKD was defined by CKD-EPI equation-calculated eGFR $<60 \mathrm{~mL} / \mathrm{min} / 1.73 \mathrm{~m}^{2}$ (16).

Thyrotropin (TSH), free triiodothyronine, and free thyroxine were measured by chemoluminescence in a modular analytics E170 analyzer (Roche Diagnostics GmbH, Mannheim, Germany). Thyroid dysfunction was considered in individuals on treatment with levothyroxine and/or thionamides or with TSH levels $>5 \mathrm{mIU} / \mathrm{L}$ or $\mathrm{TSH}<0.2 \mathrm{mIU} / \mathrm{L}$ (6).

\section{UI measurements and classification}

UI was analyzed using the modified method of Benotti and Benotti (17). The intra- and interassay coefficients of variation of the UI assay were $2.01 \%$ and $4.53 \%$, respectively. The UI assay was subjected to external quality assessments for the determination of iodine in urine by the Spanish Association of Neonatal Screening and by the Ensuring the Quality of Iodine Procedures program. All samples were analyzed in the Research Laboratory of the Hospital Regional Universitario de Málaga (Spain).

UI levels were classified according to current WHO, UNICEF, and the Iodine Global Network (formerly International Council for the Control of Iodine Deficiency Disorders) recommendations (1): $<50 \mu \mathrm{g} / \mathrm{L}$ moderate-severe deficiency, 50-99 $\mu \mathrm{g} / \mathrm{L}$ mild deficiency, 100-199 $\mu \mathrm{g} / \mathrm{L}$ adequate, 200-299 $\mu \mathrm{g} / \mathrm{L}$ above requirements, and $\geq 300 \mu \mathrm{g} / \mathrm{L}$ excessive. UI levels in this population (Di@bet.es) and its conditioning factors have been previously reported (7).

\section{Follow-up and assessment of fatal events}

Mortality data were ascertained on December 31, 2016 by the National Spanish Statistics Institute (Instituto Nacional de Estadística), from information on death certificates from the national death registry. The cause of death was coded according to the International Classification of Diseases, Tenth version ICD-10 of the WHO (18). Cardiovascular death was defined with codes I00-I99 ("diseases of the circulatory system") or R96 ("other sudden death, cause unknown"). Death due to cancer was defined with the codes C00-D48 ("neoplasms").

\section{Statistical analysis}

The study population was grouped into four categories according to their UI concentrations (1). The sociodemographic characteristics of the study population as well as other covariates of interest were determined in each category. The number of events (deaths) was estimated for each group calculating the mortality rates for each 1000 inhabitant-years (95\% confidence interval [CI]). We used the Kaplan-Meier curves to describe all-cause mortality according to these categories. Cox regression analysis was used to analyze the corresponding relative risks (RRs) of death, in crude models and in multivariate models. The category with UI 100-300 $\mu \mathrm{g} / \mathrm{L}$ was used as a reference for the calculations of the RR.

As recommended, the selection of potential confounders was based on the a priori existing knowledge, rather than centered on statistical selection procedures (19-21). Potential confounders included in the model were age, sex, education level (no studies/basic/high school-college), area of residence (south/center/east/north/northeast), hypertension (yes/no), DM (yes/no), obesity (yes/no), CKD (yes/no), smoking (yes/ no), thyroid dysfunction (yes/no), prior cardiovascular disease (yes/no), prior cancer (yes/no), hypercholesterolemia (yes/no), medscore, physical activity (low/medium/high), dairy consumption ( $<1$ per day, 1 per day, $\geq 2$ per day), and iodinated salt consumption. To assure a minimum ratio of events per independent variable of 10 (22), this multivariate regression model requires a minimum of 180 events available for analyses.

Sensitivity analyses were reconducted under different assumptions: (i) excluding participants with thyroid dysfunction and (ii) excluding participants with cardiovascular disease or cancer.

All the statistical analyses were performed with IBM SPSS statistics 23.0 and Epibasic 1.0 (University of Aarhus, Nordre Ringgade, Denmark). Reported $p$-values were based on twosided tests with statistical significance set at 0.05 .

\section{Results}

\section{Clinical characteristics of the study sample according to UI categories}

The study sample comprised of 4370 individuals with a mean age of 50.4 years (age range 18-93 years) and $57.4 \%$ were female. Mean and median UI concentrations in the population at baseline were $134.7 \pm 83 \mu \mathrm{g} / \mathrm{L}$ and $117.1 \mu \mathrm{g} / \mathrm{L}$, 
respectively. Figure 2 shows the distribution of UI concentrations in the study sample. The distribution is concordant with an iodine-sufficient population with no evidence of significant overiodization. However, $29.7 \%$ of the population had mild ID (UI 50-99 $\mu \mathrm{g} / \mathrm{L}$ ) and $9.7 \%$ had ID that was moderate-severe (UI $<50 \mu \mathrm{g} / \mathrm{L}$ ).

Table 1 shows the clinical characteristics and the distribution of the covariates in the sample according to UI concentrations. There were no significant differences in the age and sex between groups. There were small differences in the education level, with a higher proportion of individuals without studies in both the categories with very low $(<50 \mu \mathrm{g} / \mathrm{L})$ and excessive UI $(\geq 300 \mu \mathrm{g} / \mathrm{L})$. There was also an imbalance in the distribution of the area of residence across the categories. The prevalence of cardiovascular risk factors and CKD was similar between groups. Also, there were no significant differences regarding adherence to med diet, physical activity, or in the proportion of individuals reporting a previous history of cardiovascular disease or cancer. There was however a clearly higher proportion of individuals with thyroid dysfunction in the excessive UI ( $\geq 300 \mu \mathrm{g} / \mathrm{L}$ ) category than in the rest of the categories. As expected, there was a strong association between the UI levels and the consumption of iodine salt and dairy products.

\section{Ul categories and mortality}

Overall, a total of 254 deaths in 31.901 person-years of follow-up were recorded. The causes of death were cardiovascular, 71 (28\%); cancer, 85 (33.5\%); and other causes, 98 $(38.5 \%)$. The mean duration of follow-up was 7.3 years.

Table 2 shows the mortality rates and hazard ratios (HRs) for total mortality, and cardiovascular and cancer mortality in the participants grouped in categories according to their UI concentrations. In unadjusted models, participants with moderate-severe ID $(<50 \mu \mathrm{g} / \mathrm{L})$ had a $70 \%$ relatively high hazard of all-cause mortality compared with those with adequate iodine nutrition (100-300 $\mu \mathrm{g} / \mathrm{L})$. There was also a nonsignificant intermediate increase in the hazard $(29 \%)$ in the category with mild ID (50-99 $\mu \mathrm{g} / \mathrm{L})$ and a highly significant dose-response relation across the categories with normal (100-300 $\mu \mathrm{g} / \mathrm{L})$, mild (50-99 $\mu \mathrm{g} / \mathrm{L})$, and moderatesevere $(<50 \mu \mathrm{g} / \mathrm{L})$ ID ( $p$ for trend 0.004$)$. There was no significant increase in the mortality hazards in the category with excessive UI ( $\geq 300 \mu \mathrm{g} / \mathrm{L})$. Multivariate adjustment of the analyses did not induce any modification in the results.

Figure 3 includes the results of sensitivity analyses conducted repeating the cox regression models for total mortality in different scenarios (all population, excluding prevalent thyroid dysfunction and excluding prevalent cardiovascular disease or cancer). Apart from some minor changes, the direction of the results was similar, and in all scenarios, a mortality excess in the moderate-severe ID category could be observed.

Figure 4 graphically shows the Kaplan-Meier curves for total mortality incidence according to UI groups, showing an increase in the mortality curve in the category with UI $<50 \mu \mathrm{g} / \mathrm{L}$ during follow-up, which was already apparent after four years of follow-up.

Specific analysis by causes of mortality was limited due to the low number of estimates available. Acknowledging this limitation, the analysis suggested a marked increase in cardiovascular mortality, associated with ID (Table 2). Compared with the reference, cardiovascular mortality crude HRs were increased 2.1-fold in the category with mild ID (50$99 \mu \mathrm{g} / \mathrm{L})$, whereas moderate-severe ID $(<50 \mu \mathrm{g} / \mathrm{L})$ was associated with a 2.4-fold increase. Again, there was a highly significant dose-response relation in the hazards across these categories $(p=0.002)$. At higher UI $(>300 \mu \mathrm{g} / \mathrm{L})$, there was also a $42 \%$ increase in the mortality risk, although the results were not significant. After multivariate adjustment, only moderate-severe deficiency $(<50 \mu \mathrm{g} / \mathrm{L})$ was significantly associated with an increase in the mortality risk (RR 2.38 vs. reference), although a significant trend remained.

Unlike what was observed for cardiovascular mortality, no significant associations between UI and cancer mortality were observed, neither in the crude nor in the multivariate models (Table 2).

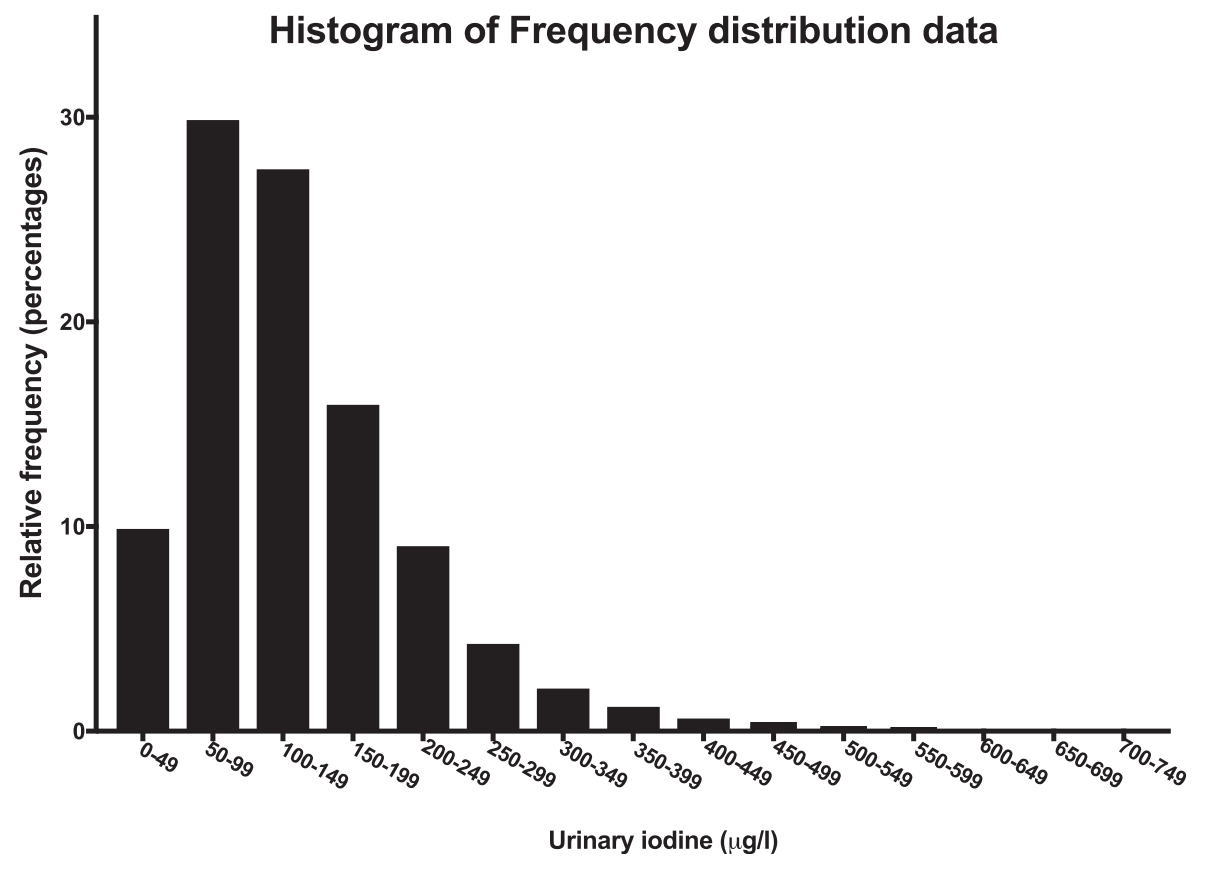

FIG. 2. Distribution of the UI concentrations in the study sample $(n=4370)$. UI, urinary iodine. 
Table 1. Baseline Characteristics of the Study Sample According to Urinary Iodine Concentrations

\begin{tabular}{|c|c|c|c|c|c|}
\hline & \multicolumn{4}{|c|}{ Urinary iodine $(\mu g / L)$} & \multirow{2}{*}{$\begin{array}{c}\mathrm{p} \text { Value } \\
\text { for difference }\end{array}$} \\
\hline & $<50$ & $50-100$ & $100-300$ & $>300$ & \\
\hline Number & 426 & 1299 & 2454 & 191 & \\
\hline Age (years) & $50.3 \pm 16.4$ & $49.9 \pm 16.5$ & $50.5 \pm 16.9$ & $52.6 \pm 16.5$ & 0.217 \\
\hline Sex (female) $(\%)$ & 57.0 & 57.0 & 57.4 & 60.7 & 0.804 \\
\hline \multicolumn{6}{|l|}{ Educational level $(\%)$} \\
\hline No studies & 16.3 & 12.2 & 11.4 & 18.3 & \\
\hline Basic & 47.2 & 49.4 & 47.9 & 50.3 & 0.004 \\
\hline High school-college & 36.6 & 38.4 & 40.5 & 31.4 & \\
\hline \multicolumn{6}{|l|}{ Area of residence $(\%)$} \\
\hline North & 22.1 & 10.5 & 8.2 & 12.6 & \\
\hline Center & 25.1 & 26.1 & 28.0 & 21.5 & $<0.001$ \\
\hline Northeast & 16.4 & 17.2 & 16.9 & 18.3 & \\
\hline East & 11.7 & 11.1 & 14.4 & 17.8 & \\
\hline South & 24.6 & 35.2 & 32.4 & 29.8 & \\
\hline Smoking $(\%)$ & 25.9 & 26.2 & 26.0 & 25.1 & 0.992 \\
\hline Hypertension $(\geq 140 / 90)(\%)$ & 47.3 & 45.6 & 43.8 & 47.6 & 0.366 \\
\hline Diabetes (WHO 1999) (\%) & 15.5 & 14.1 & 12.4 & 13.1 & 0.209 \\
\hline Obesity $(\%)$ & 29.2 & 30.2 & 31.5 & 27.7 & 0.553 \\
\hline Hypercholesterolemia ( $\geq 240 \mathrm{mg} / \mathrm{dL})(\%)$ & 21.2 & 25.4 & 26.2 & 25.3 & 0.207 \\
\hline CKD $(e G F R<60 \mathrm{~mL} / \mathrm{min})(\%)$ & 5.9 & 7.6 & 6.7 & 7.0 & 0.642 \\
\hline Thyroid dysfunction (\%) & 8.1 & 7.1 & 11.9 & 24.2 & $<0.001$ \\
\hline Mediterranean diet score & $7.8 \pm 1.8$ & $7.7 \pm 1.8$ & $7.8 \pm 1.7$ & $7.9 \pm 1.8$ & 0.375 \\
\hline \multicolumn{6}{|l|}{ Physical activity (SF-IPAQ) (\%) } \\
\hline Low & 39.2 & 44.3 & 42.4 & 41.4 & \\
\hline Medium & 38.9 & 34.6 & 32.8 & 37.2 & \\
\hline High & 21.9 & 21.1 & 24.8 & 21.5 & 0.053 \\
\hline Previous cardiovascular disease $(\%)$ & 5.2 & 6.6 & 7.4 & 7.9 & 0.358 \\
\hline Previous history of cancer $(\%)$ & 1.2 & 0.8 & 1.3 & 1.6 & 0.652 \\
\hline Iodized salt intake $(\%)$ & 32.8 & 33.4 & 42.3 & 51.3 & $<0.001$ \\
\hline \multicolumn{6}{|l|}{ Dairy consumption (\%) } \\
\hline$<1$ Per day & 17.0 & 11.2 & 8.7 & 8.4 & \\
\hline 1 Per day & 24.3 & 22.3 & 21.0 & 20.9 & \\
\hline$\geq 2$ Per day & 58.7 & 66.5 & 70.3 & 70.7 & $<0.001$ \\
\hline
\end{tabular}

CKD, chronic kidney disease; eGFR, estimated glomerular filtration rate; SF-IPAQ, short form of the International Physical Activity Questionnaire; WHO, World Health Organization.

\section{Discussion}

Our results, evaluating a large representative sample of the Spanish adult population with adequate iodine nutrition monitored during an average follow-up of 7.3 years, showed an association between moderate-severe ID and mortality that remained after the adjustment for multiple potential confounders. To the best of our knowledge, this association had not been previously described, and, if confirmed, could have important public health implications.

Despite our results being limited due to the low number of estimates available, the specific analyses by causes of mortality suggest that the association between ID and mortality was mainly driven by cardiovascular causes. This fact, along with the apparent independence of the association with the presence of thyroid dysfunction at baseline, makes us hypothesize about possible extrathyroid mechanisms with impact on the cardiovascular system as possible mechanisms of this association.

In this sense, several mechanisms could be involved:

(i) Iodine has well-known antioxidant and antiinflammatory effects (23). Micromolar amounts of iodine decrease damage by free oxygen radicals and increase the total antioxidant status in human serum
(24). It is also well established that povidone-iodine exerts an anti-inflammatory action by neutralizing radical oxygen species (25). Previous experimental studies conducted by our group (26) demonstrated that a daily dose of 100,200 , or $300 \mathrm{mg}$ of iodide in the form of potassium iodide for six months did not modify thyroid function, but had some anti-inflammatory effects; on day 60 of the treatment, UI concentration correlated with C-reactive protein $(r 0.461, p=0.018)$, and with the changes produced in $\alpha 1$-antitrypsin $(r$ $0.475, p=0.014)$ and ceruloplasmin $(r 0.599, p=0.001)$. Another previous study by our group also demonstrated that iodine is involved in the regulation of oxidative stress and adiponectin levels in human breast milk (27).

(ii) Hemodynamic effects: Iodinated soluble radiographic contrast media induce vasodilatation, which is associated with increased blood flow, decreases in vascular peripheral resistance, and variations in systemic and peripheral arterial blood pressure (28). It is not clear if iodine itself can exert some of these effects. It is noteworthy that iodine infusions have been shown to reduce heart damage by as much as $75 \%$ in a mouse model of acute myocardial infarction (29). 
Table 2. Cox Proportional Hazard Ratios (95\% Confidence Intervals) for All-Cause, Cardiovascular, and Cancer Mortality According to Urinary Iodine Categories (World Health Organization-United Nations International Children's Emergency Fund)*

\begin{tabular}{|c|c|c|c|c|c|}
\hline & \multicolumn{4}{|c|}{ Urinary iodine $(\mu g / L)$} & \multirow{2}{*}{$\underset{\text { for trend }}{\mathrm{p}}$} \\
\hline & $<50$ & $50-99$ & $100-299$ & $\geq 300$ & \\
\hline Patients $(n)$ & 426 & 1299 & 2454 & 191 & \\
\hline \multicolumn{6}{|l|}{ All-cause mortality } \\
\hline Deaths $(n)$ & 36 & 84 & 124 & 10 & \\
\hline Mortality/1000 person-years [CI] & $11.8[8.2-16.3]$ & $8.9[7.1-11.0]$ & $6.9[5.8-8.2]$ & $7.2[3.4-13.2]$ & \\
\hline RR crude $[\mathrm{CI}]$ & $1.71[1.18-2.48]$ & $1.29[0.97-1.7]$ & 1 (reference) & $1.04[0.54-1.98]$ & 0.004 \\
\hline RR multivariate $[\mathrm{CI}]$ & $1.71[1.12-2.61]$ & $1.28[0.94-1.75]$ & 1 (reference) & $1.07[0.54-2.15]$ & 0.010 \\
\hline \multicolumn{6}{|l|}{ Cardiovascular mortality } \\
\hline Deaths $(n)$ & 11 & 30 & 27 & 3 & \\
\hline Mortality/1000 person-years [CI] & $3.6[1.8-6.4]$ & $3.2[2.1-4.5]$ & $1.5[1.0-2.2]$ & $2.2[0.4-6.3]$ & \\
\hline RR crude $[\mathrm{CI}]$ & $2.40[1.19-4.85]$ & $2.10[1.25-3.54]$ & 1 (reference) & $1.43[0.43-4.72]$ & 0.002 \\
\hline RR multivariate $[\mathrm{CI}]$ & $2.38[1.05-5.40]$ & $1.82[1.00-3.32]$ & 1 (reference) & $1.58[0.46-5.42]$ & 0.011 \\
\hline \multicolumn{6}{|l|}{ Cancer mortality } \\
\hline Deaths $(n)$ & 11 & 26 & 44 & 4 & \\
\hline Mortality/1000 person-years [CI] & $3.6[1.8-6.4]$ & $2.8[1.8-4.0]$ & $2.5[1.8-3.3]$ & $2.9[0.8-7.4]$ & \\
\hline RR crude $[\mathrm{CI}]$ & $1.47[0.76-2.85]$ & $1.12[0.69-1.82]$ & 1 (reference) & $1.17[0.42-3.25]$ & 0.314 \\
\hline $\mathrm{RR}$ multivariate $[\mathrm{CI}]$ & $1.33[0.62-2.82]$ & $1.07[0.63-1.83]$ & 1 (reference) & $1.31[0.46-3.74]$ & 0.443 \\
\hline
\end{tabular}

*Reference (1).

Multivariate: age, sex, education level (no studies/basic/high school-college), hypertension (yes/no), diabetes (yes/no), obesity (yes/no), ckd (yes/no), smoking (yes/no), thyroid dysfunction (yes/no), prior cardiovascular disease (yes/no), prior cancer (yes/no), hypercholesterolemia (yes/no), area of residence (south/center/east/north/northeast), Med_score, SF-IPAQ (low/medium/high), dairy consumption ( $<1$ per day, 1 per day, $\geq 2$ per day), iodinated salt consumption (yes/no)

In bold $p<0.05$ versus UI 100-299 $\mu \mathrm{g} / \mathrm{L}$ (reference)

${ }^{\mathrm{a}} p$ for trend across categories with UI 100-299 $\mu \mathrm{g} / \mathrm{L}$ (reference), 50-99 $\mu \mathrm{g} / \mathrm{L}$, and $<50 \mu \mathrm{g} / \mathrm{L}$.

RR, relative risk; CI, 95\% confidence interval; UI, urinary iodine.

(iii) Antiatherosclerotic effects: ID has also been associated with dyslipidemia (30), and iodine treatment has been shown to reduce serum lipid levels $(31,32)$. Animal studies, performed as early as the 1930s, clearly demonstrated that iodine compounds can prevent the development of atherosclerosis in rabbits $(33,34)$. Also at the epidemiological level, low iodine levels have been associated with an increased prevalence of coronary artery disease in adults without thyroid dysfunction (35).

Although some of these mechanisms could theoretically explain an effect of ID in the cardiovascular system independently of thyroid function, it is also noteworthy that

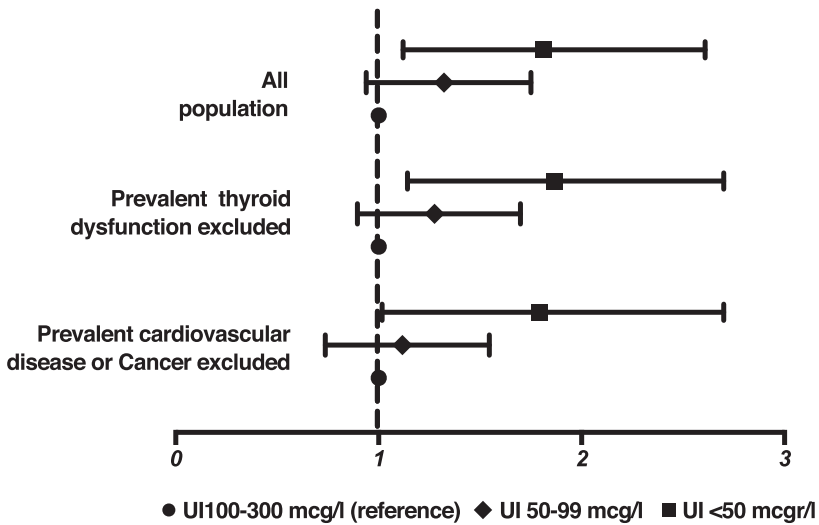

FIG. 3. All-cause mortality according to UI categories in different scenarios. Data show relative risk for total mortality and $95 \%$ confidence interval in multivariate-adjusted cox models. although we controlled our analyses by prevalent thyroid dysfunction at baseline, we cannot disregard an increased incidence of thyroid dysfunction during follow-up as a mediator of the association between ID and mortality. Moreover, even in subjects with normal thyroid hormone levels, ID could be associated with insufficient cardiac tissue levels of thyroid hormones, as has been addressed in animal models in studies by Escobar del Rey et al. (36).

Finally, different studies have suggested an association between ID and breast and prostate cancer (37-39). This antineoplastic effect has been hypothesized as being caused by different mechanisms and pathways. The oxidized iodine dissipates the mitochondrial membrane potential, thereby triggering mitochondrion-mediated apoptosis. Another mechanism would be iodolipid formation and the activation of peroxisome proliferator-activated receptors type gamma, which triggers the BAX-caspase apoptotic pathway (40). Although in our study we did not observe an increase in cancer mortality, the low statistical power of the analysis does not allow us to draw any definitive conclusion.

It is noteworthy that the descriptive design of our study does not allow us to confirm or reject any of these hypotheses to explain our results that we present as merely speculative.

To the best of our knowledge, there is only one previous epidemiological study assessing the association between iodine status and mortality with a prospective design and interestingly, the results are not concordant with our study (41). Inoue et al. (41) estimated mortality risks according to UI concentrations utilizing a nationally representative sample of 12,264 adults aged 20-80 years enrolled in the National Health and Nutrition Examination Survey III over a median follow-up of 19.2 years. According to their results, 
FIG. 4. The Kaplan-Meier curves for total mortality incidence according to UI concentrations. Color images are available online.

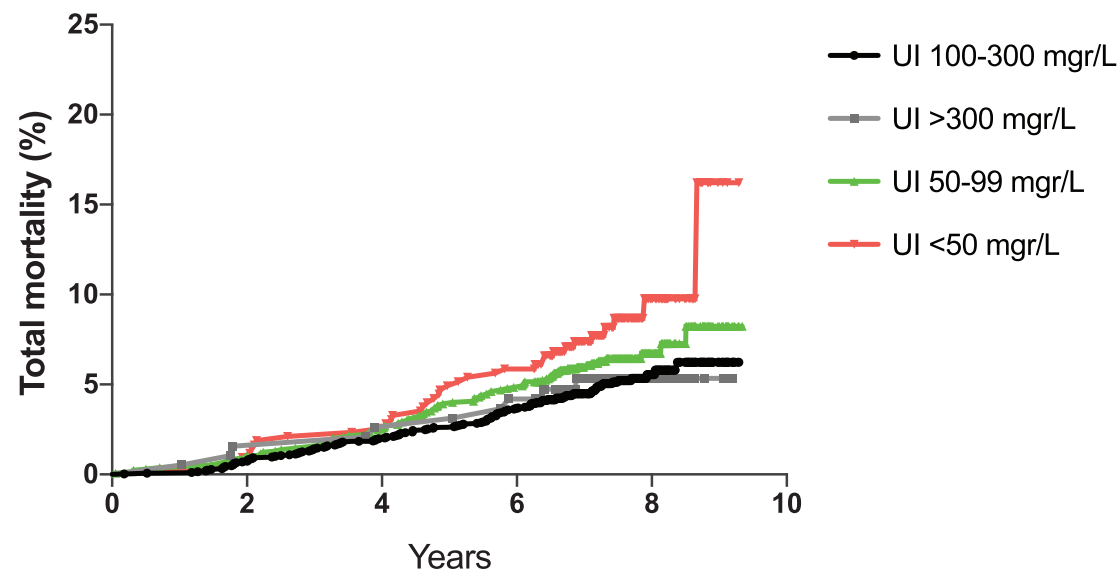

Third, unlike the Inoue et al. (41) study, we were not able participants with excess iodine exposure (UI $>400 \mu \mathrm{g} / \mathrm{L}$ ) were at a higher risk of all-cause mortality compared with those with adequate iodine nutrition (HR, 1.19; [CI 1.041.37]), whereas low UI concentration was not associated with an increased mortality.

Differences in the background population, including different iodine nutrition status in the United States compared with the Spanish population, differences in diet, could partially account for these differences. Also, it is known that the susceptibility of individuals to excessive or insufficient iodine intake is dependent on the geographical area of residence, and this information was not available in the Inoue et al. (41) study, hence analyses could not be suitably adjusted accordingly. It also seems to us that a long follow-up of 19.2 years makes more likely that a shift to an increased intake of iodine in the ID group during time could have occurred, potentially biasing the mortality estimates toward null. There are also other differences in the statistical approach between the studies.

Although some of these factors could be considered partially explanatory, we do not have a definitive explanation to account for the differences in the results of these two studies, and clearly more data from other prospective studies are necessary.

It is interesting to note that we were not able to study the group with very high UI $(\geq 400 \mu \mathrm{g} / \mathrm{L})$, associated with an increased mortality in the Inoue et al. (41) study, due to the very low number of subjects in that group. so Therefore, we cannot discard or confirm an increased mortality in this segment of the population.

Our study has several limitations. First, iodine status was estimated only from a single spot urine measurement. While $\mathrm{UI}$ in spot samples is a well-validated biomarker of iodine status for population assessments (1), individual assessment is challenging, and probably requires repeated samples to account for intraindividual day-to-day variability (42-44). Future studies should try to overcome this limitation by repeating UI assessments in at least part of the study population.

Second, we excluded from analyses any participants under amiodarone treatment, but could not exclude the possibility that participants had received iodinated contrast and both patients affected by cancer or cardiovascular disease may have had iodinated contrast computed tomography scans or angiography. Prevalent diagnosis of cancer or cardiovascular disease was introduced in the analysis as a covariate. Also, sensitivity analyses excluding participants with these diagnoses showed similar results. to adjust the results by sodium intake, but as iodine intake is strongly linked to sodium intake (in the form of iodized salt) (45) and sodium excess is associated with a higher risk of hypertension and cardiovascular disease (46), not including this variable in the analyses could, if anything, most likely generate a bias toward null.

Finally, the main limitation lies in the relatively small sample size with limited number of events available for analyses and in the observational cohort nature of the design, hence we cannot establish causal associations or exclude residual confounding factors.

In conclusion, our study shows an association between ID and mortality in Spanish adults, which seems to be driven mostly by cardiovascular causes. The discrepancy with previous studies, and the limited sample size and number of events, stress the need for further studies to clarify the relation between iodine status and mortality and cardiovascular disease in the general population.

\section{Acknowledgments}

We acknowledge the primary care managers and personnel of the participating health centers, all the nurses and dietitians who made the Di@bet.es study fieldwork possible (I. Alonso, A. Arocas, R. Badia, C.M. Bixquert, N. Brito, D. Chaves, A. Cobo, L. Esquius, I. Guillén, E. Mañas, A.M. Megido, N. Ojeda, R.M. Suarep, M.D. Zomeño). We especially thank all the people who participated voluntarily in the study. We are indebted to the Andalusian Biobank and IDIBAPS Biobank, integrated in the Spanish National Biobank Network, for the sample procurement.

\section{Author Disclosure Statement}

There is no competing financial interest that could be perceived as prejudicing the impartiality of the research reported.

\section{Funding Information}

Centro de Investigación Biomédica en Red de Diabetes y Enfermedades Metabólicas Asociadas (Ministerio de Economía, Industria y Competitividad-Instituto de Salud Carlos III), Instituto de Salud Carlos III (PI11-02755), (PI17-02136), Consejería de Salud y familias (PI-0144-2018), European Regional Development Fund "A way to build Europe." 


\section{References}

1. World Health Organization, UNICEF, International Council for Control of Iodine Deficiency Disorders 2007. Assessment of iodine deficiency disorders and monitoring their elimination: A guide for programme managers, Third edition. World Health Organization, Geneva, Switzerland. Available at https://apps.who.int/iris/bitstream/handle/10665/ 43781/9789241595827_eng.pdf (accessed September 2, 2020).

2. Andersson M, de Benoist B, Rogers L 2010 Epidemiology of iodine deficiency: salt iodisation and iodine status. Best Pract Res Clin Endocrinol Metab 24:1-11.

3. Vila L, Lucas A, Donnay S, de la Vieja A, Wengrovicz S, Santiago P, Bandrés O, Velasco I, Garcia-Fuentes E, Ares S, Moreno Navarro JC, Espada M, Muñoz A, Galofré JC, Puig-Domingo M 2020 Iodine nutrition status in Spain needs for the future. Endocrinol Diabetes Nutr 67:61-69.

4. UNICEF-WHO Joint Committee on Health Policy Special Session 1994 World Summit for Children-Mid-Decade Goal: Iodine Deficiency Disorders (IDD). Geneva, Switzerland. Available at http://www.a2zproject.org/ a2zorg/ pdf/World\%20Summit \%20for\%20Children-\%20Iodine $\%$ 20Deficiency\%20Disorders.pdf (accessed September 2, 2020).

5. Soriguer F, Goday A, Bosch-Comas A, Bordiú E, CallePascual A, Carmena R, Casamitjana R, Castaño L, Castell C, Catalá M, Delgado E, Franch J, Gaztambide S, Girbés J, Gomis R, Gutiérrez G, López-Alba A, Martínez-Larrad MT, Menéndez E, Mora-Peces I, Ortega E, Pascual-Manich G, Rojo-Martínez G, Serrano-Rios M, Valdés S, Vázquez JA, Vendrell J 2012 Prevalence of diabetes mellitus and impaired glucose regulation in Spain: the di@bet.es study. Diabetologia 55:88-93.

6. Valdés S, Maldonado-Araque C, Lago-Sampedro A, Lillo JA, Garcia-Fuentes E, Perez-Valero V, Gutierrez-Repiso C, Ocon-Sanchez P, Goday A, Urrutia I, Peláez L, CallePascual A, Bordiú E, Castaño L, Castell C, Delgado E, Menendez E, Franch J, Gaztambide S, Girbés J, Ortega E, Lopez-Alba A, Chaves FJ, Vendrell J, Chacón MR, Soriguer F, Rojo-Martínez G 2017 Population-based national prevalence of thyroid dysfunction in Spain and associated factors: study. Thyroid 27:156-166.

7. Soriguer F, García-Fuentes E, Gutierrez-Repiso C, RojoMartínez G, Velasco I, Goday A, Bosch-Comas A, Bordiú E, Calle A, Carmena R, Casamitjana R, Castaño L, Castell C, Catalá M, Delgado E, Franch J, Gaztambide S, Girbés J, Gomis R, Gutiérrez G, López-Alba A, Martínez-Larrad MT, Menéndez E, Mora-Peces I, Ortega E, Pascual-Manich G, Serrano-Rios M, Valdés S, Vázquez JA, Vendrell J 2012 Iodine intake in the adult population. Di@bet.es study. Clin Nutr 31:882-888.

8. World Medical Association 2013. Declaration of Helsinki: Ethical Principles for Medical Research Involving Human Subjects. JAMA 310:2191-2194.

9. Schröder H, Fitó M, Estruch R, Martínez-González MA, Corella D, Salas-Salvadó J, Lamuela-Raventós R, Ros E, Salaverría I, Fiol M, Lapetra J, Vinyoles E, Gómez-Gracia E, Lahoz C, Serra-Majem L, Pintó X, Ruiz-Gutierrez V, Covas M-I 2011 A short screener is valid for assessing Mediterranean diet adherence among older Spanish men and women. J Nutr 141:1140-1145.

10. IPAQ Group. International physical activity questionnaire. Available at www.ipaq.ki.se (accessed September 2, 2020).

11. WHO 2000 Obesity: preventing and managing the global epidemic. Report of a WHO Consultation (WHO Technical
Report Series 894). World Health Organization, Geneva, Switzerland. Available at https://www.who.int/nutrition/ publications/obesity/WHO_TRS_894/en/ (accessed September 2, 2020).

12. Chobanian AV, Bakris GL, Black HR, Cushman WC, Green LA, Izzo JL, Jones DW, Materson BJ, Oparil S, Wright JT, Roccella EJ, Joint National Committee on Prevention, Detection, Evaluation, and Treatment of High Blood Pressure. National Heart, Lung, and Blood Institute, National High Blood Pressure Education Program Coordinating Committee 2003 Seventh report of the joint national committee on prevention, detection, evaluation, and treatment of high blood pressure. Hypertension 42:12061252.

13. Alberti KG, Zimmet PZ 1998 Definition, diagnosis and classification of diabetes mellitus and its complications. Part 1: diagnosis and classification of diabetes mellitus provisional report of a WHO consultation. Diabet Med 15: 539-553.

14. Expert Panel on Detection, Evaluation, and Treatment of High Blood Cholesterol in Adults 2001 Executive Summary of The Third Report of The National Cholesterol Education Program (NCEP) Expert Panel on Detection, Evaluation, and Treatment of High Blood Cholesterol in Adults (Adult Treatment Panel III). JAMA 285:2486-2497.

15. Bartels H, Böhmer M 1971 Micro-determination of creatinine [in German]. Clin Chim Acta 32:81-85.

16. Levey AS, Coresh J, Balk E, Kausz AT, Levin A, Steffes MW, Hogg RJ, Perrone RD, Lau J, Eknoyan G, National Kidney Foundation 2003 National Kidney Foundation practice guidelines for chronic kidney disease: evaluation, classification, and stratification. Ann Intern Med 139:137147.

17. Benotti J, Benotti N 1963 Protien-bound iodine, total iodine, and butanol-extractable iodine by automation. Clin Chem 12:408-416.

18. Bramer GR 1988 International statistical classification of diseases and related health problems-tenth revision. World Heal Stat Q 41:32-36.

19. Greenland S, Neutra R 1980 Control of confounding in the assessment of medical technology. Int J Epidemiol 9: 361-367.

20. Kenneth JR, Greenland S 1998 Modern Epidemiology, Second edition. Lippincott-Raven, Philadelphia.

21. Hernán MA, Hernández-Díaz S, Werler MM, Mitchell AA 2002 Causal knowledge as a prerequisite for confounding evaluation: an application to birth defects epidemiology. Am J Epidemiol 155:176-184.

22. Peduzzi P, Concato J, Feinstein AR, Holford TR 1995 Importance of events per independent variable in proportional hazards regression analysis II. Accuracy and precision of regression estimates. J Clin Epidemiol 48: 1503-1510.

23. Aceves C, Anguiano B, Delgado G 2013 The extrathyronine actions of iodine as antioxidant, apoptotic, and differentiation factor in various tissues. Thyroid 23:938946.

24. Winkler R, Griebenow S, Wonisch W 2000 Effect of iodide on total antioxidant status of human serum. Cell Biochem Funct 18:143-146.

25. Beukelman CJ, van den Berg AJJ, Hoekstra MJ, Uhl R, Reimer K, Mueller S 2008 Anti-inflammatory properties of a liposomal hydrogel with povidone-iodine (Repithel) for wound healing in vitro. Burns 34:845-855. 
26. Soriguer F, Gutiérrez-Repiso C, Rubio-Martin E, Linares F, Cardona I, López-Ojeda J, Pacheco M, González-Romero S, Garriga MJ, Velasco I, Santiago P, García-Fuentes E 2011 Iodine intakes of $100-300 \mu \mathrm{g} / \mathrm{d}$ do not modify thyroid function and have modest anti-inflammatory effects. Br J Nutr 105:1783-1790.

27. Gutiérrez-Repiso C, Velasco I, Garcia-Escobar E, GarciaSerrano S, Rodríguez-Pacheco F, Linares F, Ruiz de Adana MS, Rubio-Martin E, Garrido-Sanchez L, Cobos-Bravo JF, Priego-Puga T, Rojo-Martinez G, Soriguer F, GarcíaFuentes E 2014 Does dietary iodine regulate oxidative stress and adiponectin levels in human breast milk? Antioxid Redox Signal 20:847-853.

28. Morcos SK, Dawson P, Pearson JD, Jeremy JY, Davenport AP, Yates MS, Tirone P, Cipolla P, De Haën C, Muschick P, Krause W, Refsum H, Emery CJ, Liss P, Nygren A, Haylor J, Pugh ND, Karlsson JOG 1998 The haemodynamic effects of iodinated water soluble radiographic contrast media: a review. Eur J Radiol 29:31-46.

29. Iwata A, Morrison ML, Roth MB 2014 Iodide protects heart tissue from reperfusion injury. PLoS One 9: e112458.

30. Lee KW, Shin D, Song WO 2016 Low urinary iodine concentrations associated with dyslipidemia in US adults. Nutrients 8:171.

31. Rönnefarth G, Kauf E, Deschner F, Forberger M 1996 Therapy of iodine deficiency goiter in adolescents with iodine or a combination of iodine and levothyroxine with special reference to lipid parameters [in German]. Klin Padiatr 208: 123-128.

32. Herter-Aeberli I, Cherkaoui M, El Ansari N, Rohner R, Stinca S, Chabaa L, von Eckardstein A, Aboussad A, Zimmermann MB 2015 Iodine supplementation decreases hypercholesterolemia in iodine-deficient, overweight women: a randomized controlled trial. J Nutr 145: 2067-2075.

33. Turner KB 1933 Studies on the prevention of cholesterol atherosclerosis in rabbits: I. The effects of whole thyroid and of potassium iodide. J Exp Med 58:115-125.

34. Meeker DR, Kesten HD, Jobling JW 1935 Effect of iodine on cholesterolinduced atherosclerosis. Arch Pathol 20:337342.

35. Tran H V, Erskine NA, Kiefe CI, Barton BA, Lapane KL, Do VTH, Goldberg RJ 2017 Is low iodine a risk factor for cardiovascular disease in Americans without thyroid dysfunction? Findings from NHANES. Nutr Metab Cardiovasc Dis 27:651-656.

36. Escobar del Rey F, Ruiz de Oña C, Bernal J, Obregón MJ, Morreale de Escobar G 1989 Generalized deficiency of 3,5,3'-triiodo-L-thyronine (T3) in tissues from rats on a low iodine intake, despite normal circulating T3 levels. Acta Endocrinol (Copenh) 120:490-498.
37. Hoption Cann SA, Qiu Z, van Netten C 2007 A prospective study of iodine status, thyroid function, and prostate cancer risk: follow-up of the First National Health and Nutrition Examination Survey. Nutr Cancer 58:28-34.

38. Cann SA, van Netten JP, van Netten C 2000 Hypothesis: iodine, selenium and the development of breast cancer. Cancer Causes Control 11:121-127.

39. Aranda N, Sosa S, Delgado G, Aceves C, Anguiano B 2013 Uptake and antitumoral effects of iodine and 6-iodolactone in differentiated and undifferentiated human prostate cancer cell lines. Prostate 73:31-41.

40. Singh P, Godbole M, Rao G, Annarao S, Mitra K, Roy R, Ingle A, Agarwal G, Tiwari S 2011 Inhibition of autophagy stimulate molecular iodine-induced apoptosis in hormone independent breast tumors. Biochem Biophys Res Commun 415:181-186.

41. Inoue K, Leung AM, Sugiyama T, Tsujimoto T, Makita N, Nangaku M, Ritz BR 2018 Urinary iodine concentration and mortality among U.S. adults. Thyroid 28:913-920.

42. Andersen S, Karmisholt J, Pedersen KM, Laurberg P 2008 Reliability of studies of iodine intake and recommendations for number of samples in groups and in individuals. $\mathrm{Br} \mathbf{J}$ Nutr 99:813-818.

43. König F, Andersson M, Hotz K, Aeberli I, Zimmermann MB 2011 Ten repeat collections for urinary iodine from spot samples or 24-hour samples are needed to reliably estimate individual iodine status in women. J Nutr 141: 2049-2054.

44. Zimmermann MB, Andersson M 2012 Assessment of iodine nutrition in populations: past, present, and future. Nutr Rev 70:553-570.

45. Grzesiuk W, Kondracka A, Słoń M, Wojda M, Nauman J 2002 Salt iodination as a effective method of iodine supplementation. Med Sci Monit 8:CR288-91.

46. O’Donnell MJ, Yusuf S, Mente A, Gao P, Mann JF, Teo K, McQueen M, Sleight P, Sharma AM, Dans A, Probstfield J, Schmieder RE 2011 Urinary sodium and potassium excretion and risk of cardiovascular events. JAMA 306: 2229-2238.

Address correspondence to: Sergio Valdés, $M D, P h D$ Department of Endocrinology and Nutrition Hospital Regional Universitario de Málagal Universidad de Málaga

IBIMA

Plaza del Hospital Civil s/n Malaga 29009 Spain

E-mail: sergio.valdes@hotmail.es 